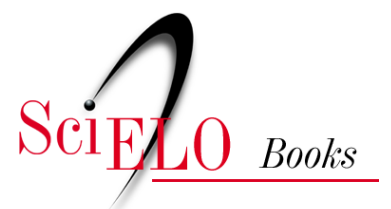

EDUFU

\title{
Teatro, jogo e brincadeira \\ uma proposta de reelaboração do cavalo-marinho em procedimentos pedagógicos para o ator
}

\author{
Mariana Oliveira
}

\section{SciELO Books / SciELO Livros / SciELO Libros}

OLIVEIRA, M. Teatro, jogo e brincadeira: uma proposta de reelaboração do cavalo-marinho em procedimentos pedagógicos para o ator. In: FLORENTINO, A., and TELLES, N., eds. Cartografias do ensino do teatro [online]. Uberlândia: EDUFU, 2008, pp. 201-208. ISBN 978-85-7078-518-3. https://doi.org/10.7476/9788570785183.0021.

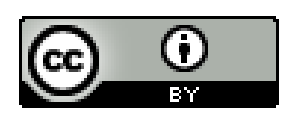

All the contents of this work, except where otherwise noted, is licensed under a Creative Commons Attribution 4.0 International license.

Todo o conteúdo deste trabalho, exceto quando houver ressalva, é publicado sob a licença Creative Commons Atribição $\underline{4.0}$.

Todo el contenido de esta obra, excepto donde se indique lo contrario, está bajo licencia de la licencia $\underline{\text { Creative Commons }}$ Reconocimento 4.0. 


\section{TEATRO, JOGO E BRINCADEIRA: \\ UMA PROPOSTA DE REELABORAÇÃO do CAVALO MARINHO \\ EM PROCEDIMENTOS PEDAGÓGICOS PARA O ATOR}

\section{Mariana Oliveira}

Este artigo apresenta parte dos resultados da pesquisa de mestrado $O$ jogo da cena do Cavalo Marinho: diálogos entre teatro e brincadeira, desenvolvida no âmbito do projeto integrado Um estudo sobre o cômico: o teatro popular no Brasil entre ritos e festas, sob orientação da Profa. Beti Rabetti (Maria de Lourdes Rabetti), no Programa de Pós-Graduação em Teatro da Uni-Rio. Através de trabalho de campo com observação participante na zona da mata norte pernambucana, especialmente na cidade de Condado, e de laboratório experimental realizado na Escola de Teatro da Uni-Rio, procurou-se discutir o lugar, no teatro, da brincadeira, categoria adotada pelos realizadores do Cavalo Marinho ao designá-lo. Manifestação espetacular de múltiplas origens, das quais aquela localizada entre os escravos nas senzalas dos engenhos canavieiros costuma ser a mais referida pelos brincadores, apresenta-se hoje principalmente por contrato nas festas de rua municipais por ocasião do Natal, do Ano Novo e das homenagens aos santos padroeiros nos meses de dezembro e janeiro.

Os diálogos travados entre os dois fenômenos, tanto no plano teórico, analítico e conceitual quanto no da experimentação prática, que em verdade ocorrem não dissociados, mas entrelaçados e de maneira orgânica, são atravessados pela noção de jogo: primeiro porque participa das essências de ambos, sendo o "próprio modo de ser da obra de arte" ${ }^{1 \text { ", }}$ e, segundo, porque se tem mostrado recorrente nas reflexões acerca do teatro contemporâneo.

As idéias gerais da brincadeira e do teatro aproximam-se em pontos que constituem também características lúdicas: faz-de-conta, universo imaginativo, estado diferenciado de presença, ambiente instável, estabelecimento de relação, harmonia, ritmo, absorção, encantamento, circunscrição espaço-temporal, capacidade agregadora, regramento, repetição, acaso, atenção, relaxamento, liberdade, ordem, crença, consciênciaª .

\footnotetext{
${ }^{1}$ GADAMER, Hans-Georg. A ontologia da obra de arte e seu significado hermenêutico. In: Verdade e método. Petrópolis: Vozes, 1997. p. 174-201.

${ }^{2}$ HUIZINGA, Johan. Homo ludens. 5. ed. São Paulo: Perspectiva, 2004. 243 p.
} 
Alguns desses fatores evidenciam-se quando o teatro funciona plenamente, quando se diz que "o jogo acontece". Um último elemento que participa tanto do ser jogo, quanto do ser teatro e do ser brincadeira é a “diversão”, isto é, uma "volta ou 'versão' de nosso ser para o ultravital ou irreal", para um mundo "diferente", termo usado pelos brincadores para designar com positividade a autonomia da brincadeira em relação às leis da realidade cotidiana. Acerca disso, vale o comentário feito por mestre Mariano Teles durante entrevista dada à autora em 31/12/04, em Chã de Camará, zona rural do município de Aliança/PE, sobre a confecção das máscaras do Cavalo Marinho:

A máscara [...] pode sair até um pouco parecida com a gente, mas ela pode sair uma coisa mais divulgada, diferente, ela pode não ficar mesmo a feição de uma pessoa $[. .$.$] a gente tem que fazer ela mais estranha [. .$.$] tem que fazer a máscara$ diferente e a gente nunca faz que nem uma obra da natureza [...] só é bonita porque é feia, que se fosse bonita, a gente não queria nem olhar.

A instauração de um ambiente especial e de um universo imaginativo faz da “cena em jogo" uma realidade autônoma, livre da preocupação de representar fielmente o que está além dela e que trabalha com o que se dá no ato, no presente. Para jogar em teatro, além de saber repetir, é necessário estar aberto para o inesperado e lidar com ele de forma não mecanizada, mas com disponibilidade e escuta. Executar opõe-se a jogar, ação que se dá consigo mesmo, com o ambiente, com o outro ator e com o público.

Após essa série de aproximações, é necessário atentar para a não identidade absoluta entre jogo, teatro e brincadeira. Se no jogo em geral todos são jogadores, no representativo, no teatro ou na instância espetacular, como a brincadeira, a ação se dá em relação a alguém:

O jogo não é mais, aqui, um mero representar-se de um movimento ordenado, nem mesmo um mero representar, no qual se revela a criança que brinca, mas é, "representando para...”. Essa indicação, própria a todo representar, também será resgatada aqui, tornando-se constitutiva para o ser da arte ${ }^{4}$.

Assim, dá-se a transformação do jogo em configuração, isto é, sua consumação em ser arte. A separação palco/platéia marca o limite entre o princípio lúdico e o jogo teatral ${ }^{5}$.

No que tange às práticas teatrais contemporâneas, incluindo as performances, percebe-se que ganham espaço reflexivo questões tais como as da presença, do imprevisto, da escuta (atores/atores, atores/espectadores, atores/ambiente) e das dualidades lúdicas evidenciadas em experiências que exploram os limites entre tempos, espaços e sujeitos reais e ficcionais.

A análise de alguns aspectos fundamentais da brincadeira do Cavalo Marinho estreita os diálogos com o fazer teatral contemporâneo:

${ }^{3}$ ORTEGA Y GASSET, José. A idéia do teatro. São Paulo: Perspectiva, 1991. p. 51

${ }^{4}$ GADAMER, 1997, p. 184, destaques da autora.

${ }^{5}$ PAVIS, Patrice. Dicionário de teatro. 2. ed. São Paulo: Perspectiva, 1999. 512 p. 
1) a abertura e a fragmentação da dinâmica de apresentação, com dissolução do encadeamento causal, mistura de gêneros e valorização do estilo épico-narrativo, remetem diretamente à estrutura não aristotélica, mas feita por colagens, justa e sobreposições, sem necessária sucessão lógica ou coerente de ações bem definidas, também encontrada nas performances e em outros exemplos da cena contemporânea;

2) a aprendizagem não sistemática, mas por bricolagem, observando a diver sidade de saberes e fontes, relaciona-se à maneira de se estudar teatro hoje, em meio a uma enormidade de estilos, escolas e tradições;

3) a configuração espacial da roda coloca atuantes e espectadores em relação diversa daquela que define espaços distintos de atividade versus pura passividade, contribuindo para a investigação contemporânea acerca das possíveis formas de relação entre atuação e recepção;

4) o modo de "colocar figura" reporta à interpretação citacional ou ilustrativa vista em muitas experiências teatrais contemporâneas nas quais não se constitui exatamente nem o personagem dramático nem o narrador, mas algo entre eles, numa função enunciativa, como a que cumpre a figura de mestre Ambrósio no Cavalo Marinho. Numa espécie de prólogo e através de mímicas e danças específicas, ele apresenta as demais figuras. Essas, próximas dos personagens-tipo, são colocadas por um pequeno número de "figureiros" ao longo de uma brincadeira, em episódios curtos, verdadeiras passagens. Mantêm-se num plano bastante superficial, não tridimensional e sem profundidade, e questionam a representação pela ambigüidade estabelecida em relação à própria pessoa do figureiro;

5) o destaque da dimensão do significante sobre a do significado constitui aspecto também verificável no teatro contemporâneo. Na brincadeira, o modo de construção poética e a repetição de trechos dialogados fazem esmaecer o sentido profundo do texto falado e chamam a atenção para sua sonoridade.

As experiências teatrais contemporâneas, como "práticas significantes"” que não visam à revelação de um sentido preexistente, mas geram uma polifonia de significados, são ainda marcadas por recorrências: paródia, citação, linguagem lírico-narrativa, tendência miscelânica, indecisão quanto ao gênero de manifestação artística, multiplicidade de referências culturais, mobilidade ou ambigüidade de sentidos (o signo perde a relação estável entre o significante e o significado), auto-ironia, tensão entre atualidade cênica e relato, problematização da representação do sujeito e da estrutura tradicional do personagem $^{8}$. Dentre elas, algumas claramente dialogam com os aspectos da brincadeira acima citados.

6 Figura é o termo utilizado no Cavalo Marinho para designar espécies de personagens-tipo, elaborados principalmente a partir de um nome enunciativo e de um roteiro de ações na roda da brincadeira. Ex.: o Soldado da Gurita vem prender os negos Mateus e Bastião, para que dêem a licença para o Capitão "dar o baile na cidade"; a Véia do Bambu vem atrás de seu pássaro perdido, a Ema, e demonstra ser muito "fogosa" diante dos homens presentes, colocando-os debaixo de sua saia.

7 PAVIS, Patrice. La herencia clásica del teatro postmoderno. In: . El teatro y su recepción, semiologia, cruce de culturas y postmodernismo. Cuba: UNEAC, $\overline{1994 . ~ p . ~ 207-223 . ~}$

${ }^{8}$ DA COSTA, José. Narração e representação do sujeito no teatro contemporâneo. O Percevejo: Revista de Teatro, Crítica e Estética, Rio de Janeiro, ano 8, n. 9, p. 3-24, 2000. 
As artes da performance também constituem espaço de releitura e rediscussão dos conceitos estruturais da cena, rompendo com a representação e aproximando-se da vida. São alguns de seus traços característicos: estrutura não aristotélica, ambigüidade entre personagem e a própria pessoa do artista, caráter de evento, de rito, dialética entre tempos e espaços ficcionais e reais, que convivem sobrepostos, relação mais mítica ou ritualística que estética entre espectador e objeto artístico, com possibilidade de maior grau de atividade daquele". Aqui, também se verificam coincidências em relação ao observado na análise da brincadeira.

Estabelecidos esses assuntos comuns, propõe-se estender os diálogos entre teatro e brincadeira para o campo da experimentação prática. Para tanto, é preciso refletir acerca da maneira de enfrentar o objeto do Cavalo Marinho:

\begin{abstract}
No que se refere à possibilidade de percepção de acervos técnicos, talvez devêssemos suspender o encantamento aflorado pela visão de uma natureza característica, e, então, indagar por um sistema de códigos, tão singulares quanto longamente elaborados. E, acredito, será através do cuidadoso exercício de compreensão e recuperação destes códigos, e através de sua precisa reelaboração em métodos e técnicas adequados à arte da cena, que um teatro popular pode vir a se articular de maneira mais efetiva, isto é, como expressão artística e criadora autônoma $[\ldots . .]^{10}$.
\end{abstract}

Ou seja, os "códigos da brincadeira" podem se oferecer para "reelaboração" no âmbito teatral, sem se deixar de atentar para o fato de que esse processo constitui “[...] não uma absorção cênica estreita e simplista de persistentes manifestações populares encontradas nas correntes artísticas ou festivas de culturas tradicionais [...]" ${ }^{11}$. Não se trata de reprodução, mas de um "diálogo forte" com a tradição, de maneira que sejam percebidos "códigos (persistências) e variáveis (aptas para adequações a novos tempos ou a novos sentidos)" capazes de gerar "combinações inovadoras"12. Essa experiência materializou-se no âmbito do laboratório experimental O jogo da cena do Cavalo Marinho: experimentando teatro e brincadeira.

Aqui a noção de jogo volta a ser importante, mais especificamente no modo de trabalho com os atores-pesquisadores do laboratório, que lançaram mão de diversos exercícios lúdicos reelaborados a partir do universo temático, do repertório técnico e de momentos especiais do Cavalo Marinho.

Ao longo do tempo, os jogos dramáticos e teatrais passam a desempenhar atraente função pedagógica no ensino do teatro: na década 1940, encenadores franceses criam a Educação pelo jogo dramático, estabelecendo tradição verificável nas propostas de Jean-Pierre Ryngaert ${ }^{13}$; na década de 1950, Viola Spolin constrói um sistema de jogos teatrais e improvisacionais amplamente difundido no teatro-educação; no Brasil, os exemplos d'O Tablado de Maria Clara Machado e de Augusto Boal confirmam a tendência para o recurso do jogo no ensino da linguagem teatral. O laboratório seguiu

\footnotetext{
${ }_{9}$ COHEN, Renato. Performance como linguagem. São Paulo: Perspectiva, 2002. 176 p.

${ }^{10}$ RABETTI, Beti. Memória e culturas do "popular" no teatro: o típico e as técnicas. O Percevejo: Revista de Teatro, Crítica e Estética. Rio de Janeiro, ano 8, n. 8, p. 7-8, $2000 .$.

11 RABETTI, 2000, p. 11.

12 RABETTI, 2000, p. 11-12.

${ }_{13}$ MARTINS, Marcos Bulhões. Encenação em jogo: experimento de aprendizagem e criação do teatro. São Paulo: Hucitec, 2004. 245 p.
} 
esse caminho.

Assim, redimensionou-se a noção de brincadeira, não mais exclusivamente a categoria usada pelos praticantes do Cavalo Marinho para designá-lo, mas também a própria definição para determinada maneira de se pesquisar e trabalhar em teatro. Nesta nova concepção, outros dois conceitos são fundamentais: o "estado da brincadeira" e o "corpo-que-brinca". O primeiro traduz-se por um estado de concentração relaxada ou de atenção sem tensão que ocorre em corpos conectados, trabalhando em conjunto, e o segundo refere-se ao corpo que experimenta tal estado, pronto, preciso, em escuta, e que se organiza com soltura articular, oposições segmentares e agilidade de movimentação.

O “corpo-que-brinca” avizinha-se da imediata resposta à excitação dos reflexos preconizada por Meyerhold, em 1969 e do "corpo decidido" de Barba ${ }^{14}$. Evidencia-se no trabalho energético promotor de disponibilidade física e mental para a criação, construído a partir da dança do Cavalo Marinho e, ainda, numa série de jogos úteis para o treino de habilidades específicas para um ator presente, ativo e ágil, e para o estímulo à sua capacidade imaginativa.

O trabalho energético desenvolveu-se através do treinamento na dança do Cavalo Marinho, feito livremente no espaço a partir da célula rítmica usada no "Tombo do marguio", espécie de jogo-dança em roda. No centro da roda, duplas de participantes se alternam, estabelecendo instigantes diálogos corporais, e dos "passos soltos", maneira encontrada para designar os passos de dança que constituem o repertório geral da brincadeira. Caminhando e marcando a pulsação da música, os alunos-pesquisadores acrescentavam, aos poucos, contratempos, pausas, quedas, suspensões e aproximações com colegas. Esse exercício gerou um estado de disponibilidade, tanto física, pela mobilização do corpo todo, como também de jogo, isto é, de estabelecimento de relação com o outro, através do olhar e do diálogo corporal. Desenvolveu a ampliação do campo de visão, além de um refinamento dos sentidos e da percepção, e revelou-se um jogo de presença ao requerer atenção múltipla, distribuída entre ritmo, espaço, olhar, encontro. Neste jogo de conjunto, todos marcam o tempo juntos e vigorosamente, estabelecendo conexão com a terra. A pulsação, a exaustão e o desafio diante dos limites relacionam-se à geração daquele "estado de brincadeira" comparável à diversão e ao prazer da brincadeira de criança. Em determinado momento, o corpo, impulsionado pelo diálogo com o outro e pela força coletiva, ultrapassa o estágio do cansaço para alcançar uma espécie de leveza.

Entre os outros jogos experimentados, vale comentar, especialmente, o "Tombo do marguio", o "Não pague não, Capitão!”, o "Sinhá véia, sinhá moça”, o "Capitão viu?", o "Roda de figuras” e o "Capitão mandou chamar?”. O primeiro, realizado tal qual no Cavalo Marinho, revela códigos estruturantes da brincadeira. Nele, importa não tanto o desempenho individual, mas o aspecto coletivo, como no próprio sentido de jogo:

Se considerarmos o uso da palavra jogo [...] sempre está implícito o vaivém de um movimento, o qual não está fixado em nenhum alvo, no qual termine. A isso corres-

${ }_{14}$ MEYERHOLD, V. O ator e sua atuação. In: CONRADO, Aldomar (Org.). O teatro de Meyerhold. Rio de Janeiro: Civilização Brasileira, 1969. p. 173-174; BARBA, Eugenio. A canoa de papel: tratado de antropologia teatral. São Paulo: Hucitec, 1994. p. 54. 
ponde também o originário significado da palavra jogo como dança, que sobrevive em múltiplas formas de palavras [...]. O movimento, que é jogo, não possui nenhum alvo em que termine, mas renova-se em permanente repetição. $\mathrm{O}$ movimento de vaivém é obviamente tão central para a determinação da natureza do jogo que chega a ser indiferente quem ou o que executa esse movimento. [...] $\mathrm{O}$ jogo é a consumação do movimento como tal ${ }^{15}$.

No "Tombo do marguio", jogo-dança, o vaivém do movimento é experimentado praticamente nos corpos dos jogadores-dançarinos que dispõem de uma estrutura básica de passo dentro da qual lhes é permitido o improviso. Asseguradas a continuidade e a fluência do jogo, o aspecto pessoal pode e deve inserir-se no conjunto.

O “Não pague não, Capitão!", reelaborado a partir das chamadas "cobranças" do Cavalo Marinho, realiza-se em roda ao som de música. Em determinado momento, um jogador, de "corpo decidido", entra na roda desafiando outro com o olhar. O primeiro "cobra" o segundo, ameaçando-o com rasteiras, pernadas, giros ou outros movimentos até imobilizá-lo através de uma "chave de pernas". A intenção de prender o outro gera tensão lúdica, constituindo uma das tarefas do jogo, mas não o seu único objetivo: “[...] o verdadeiro fim do jogo não é, de forma alguma, a solução dessas tarefas, mas a regulamentação e a configuração do próprio movimento do jogo" 16 .

Isto é, os jogadores devem preocupar-se com o que fazem na trajetória em direção aos fins. Assim, a alternância de dinâmicas de movimentação (rápidas ou lentas, curvilíneas ou retas), o seu uso criterioso (para distrair ou ameaçar, por exemplo), o olhar concentrado no outro, a manha, a malícia, o enfrentamento, o corpo tático, que joga para desfazer o jogo do outro, encontrando brechas para escapar quando encurralado, fazem daquele momento um acontecimento vivo e interessante.

O "Sinhá véia, sinhá moça” utiliza uma curta passagem do episódio da Véia do Bambu, figura do Cavalo Marinho, para estabelecer um jogo em roda. Uma pessoa entra e coloca uma máscara de Véia; os demais cantam anunciando a chegada de seu marido que lhe traz um presente. A Véia escolhe alguém e pergunta de que presente se trata. Repetindo-se essa dinâmica uma série de vezes, configura-se um jogo cumulativo em que o jogador que cumpre a função da Véia tem que lembrar a cada vez todos os presentes trazidos pelo marido. Além disso, porém, importa fundamentalmente que o aluno-ator construa aos poucos, na ação e na relação com os demais, a sua Véia, sem ter estabelecido a priori composição de voz ou de postura.

No “Capitão viu?” uma célula textual do diálogo entre mestre Ambrósio e Capitão, figuras do Cavalo Marinho, é reutilizada, objetivando desenvolver uma "palavra que brinca", isto é, uma palavra que segue uma estrutura pré-definida, mas que tem liberdade de variar, de improvisar, desde que de maneira precisa e sem perder de vista o roteiro. A repetição também faz com que o foco não esteja na obediência ao tempo psicológico de ação, reflexão e reação coerentes, mas na própria sonoridade gerada, na forma de se dizer. Em roda, ao som da música, um voluntário 
entra e realiza a dança de uma figura. Em seguida, pergunta ao Capitão se a reconheceu, desencadeando o diálogo pré-definido. Ao final, deve realizar a dança de outra figura e assim por diante. $\mathrm{O}$ jogador tem que ter atitude e decisão.

Os dois últimos jogos, mais propriamente de reelaboração, "Roda de figuras" e "Capitão mandou chamar?", visam à criação de novas figuras, inspiradas no repertório técnico e temático do Cavalo Marinho. No primeiro, em roda e ao som de música, uma pessoa entra realizando uma dança que revele o estado de sua figura. Os demais participantes propõem um nome significativo para aquela figura. No segundo, alguém assume a função de Capitão, dizendo para que mandou chamar aquela figura e, assim, auxiliando na definição de sua ação específica.

Além dessas atividades, exercícios improvisacionais calcados nas idéias de roteiro, repertório e figuras, à semelhança da dinâmica estudada na brincadeira do Cavalo Marinho, constituem interessante engrenagem cênica teatral que, a partir de estrutura mais ou menos fixa, oferece espaço para inúmeras novas combinações. Essa noção de improvisação como espaço combinatório assemelha-se àquela da Commedia dell'arte, cuja imagem da liberdade e da espontaneidade constitui uma falsa idéia do que, na verdade, está relacionado a uma habilidade derivada de intensa prática geradora da possibilidade de uma "composição veloz"17. Como diz mestre Antônio Teles, irmão de Mariano, deve-se "criar pela memória”, ou seja, não se trata nem de jogo totalmente livre, no qual se improvisa acerca de um tema mais ou menos definido, nem de texto ou partitura absolutamente fixos e imutáveis; trata-se de um jogar entre o roteiro e o improviso.

Assim, o modo de trabalho constituído, passível de aproveitamento em pesquisas ulteriores para elaboração de eficaz treinamento para atores, caracteriza-se, de maneira geral, pelas discussões diárias acerca do fazer, pelo trabalho coletivo, do qual a configuração dos exercícios em roda é emblemática e, ainda, pela atividade prazerosa perpassada por divertimento e comicidade.

Os elementos estéticos, o recurso da máscara, a metalinguagem, o estilo épico-narrativo integram, ainda, o "sistema de códigos" 18 da brincadeira colocado à disposição para direta utilização na cena com vistas a potencializar sua força expressiva. Os materiais do Cavalo Marinho oferecem-se, assim, como poderoso acervo "indutor", isto é, "propulsor da criação em arte"19, enriquecendo os diálogos entre brincadeira e teatro e, de maneira efetiva, as próprias práticas teatrais contemporâneas.

17 TAVIANI, Ferdinando. Once puntos para entender la improvisacion em la Commedia dell'arte. Máscara: Cuaderno Iberoamericano de Reflexion sobre Escenologia, México, ano 4, n. 21-22, p. 5, jan. 1997.

${ }_{18}$ RABETTI, 2000, p. 7.

19 RABETTI, 2000, p. 4. 


\section{REFERÊNCIAS}

BARBA, Eugenio. A canoa de papel: tratado de antropologia teatral. São Paulo: Hucitec, 1994.

COHEN, Renato. Performance como linguagem. São Paulo: Perspectiva, 2002.

DA COSTA, José. Narração e representação do sujeito no teatro contemporâneo. O Percevejo: Revista de Teatro, Crítica e Estética, Rio de Janeiro, ano 8, n. 9, p. 3-24, 2000.

GADAMER, Hans-Georg. A ontologia da obra de arte e seu significado hermenêutico. In: . Verdade e método. Petrópolis: Vozes, 1997. p. 174-201.

HUIZINGA, Johan. Homo ludens. 5. ed. São Paulo: Perspectiva, 2004.

MARTINS, Marcos Bulhões. Encenação em jogo: experimento de aprendizagem e criação do teatro. São Paulo: Hucitec, 2004.

MEYERHOLD, V. O ator e sua atuação. In: CONRADO, Aldomar (Org.). O teatro de Meyerhold. Rio de Janeiro: Civilização Brasileira, 1969. p. 173-174.

ORTEGA Y GASSET, José. A idéia do teatro. São Paulo: Perspectiva, 1991.

PAVIS, Patrice. Dicionário de teatro. 2. ed. São Paulo: Perspectiva, 1999.

PAVIS, Patrice. La herencia clásica del teatro postmoderno. In: . El teatro y su recepción, semiologia, cruce de culturas y postmodernismo. Cuba: UNEAC, 1994. p. 207-223.

RABETTI, Beti. Memória e culturas do "popular" no teatro: o típico e as técnicas. O Percevejo: Revista de Teatro, Crítica e Estética. Rio de Janeiro, ano 8, n. 8, p. 3-18, 2000.

TAVIANI, Ferdinando. Once puntos para entender la improvisacion em la Commedia dell'arte. Máscara: Cuaderno Iberoamericano de Reflexion sobre Escenologia, México, ano 4, n. 21-22, p. 4-23, jan. 1997. 